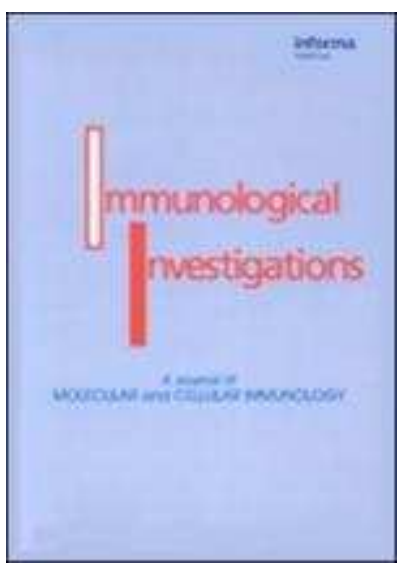

\title{
Immunogenetic profiling to predict risk of invasive fungal diseases: where are we now?
}

\begin{tabular}{|r|l|}
\hline Journal: & Immunological Investigations \\
\hline Manuscript ID: & Draft \\
\hline Manuscript Type: & Reviews \\
\hline Author: & nabmitted by the \\
\hline Complete of Authors: & $\begin{array}{l}\text { Cunha, Cristina; University of Perugia, Department of Experimental } \\
\text { Medicine and Biochemical Sciences } \\
\text { Aversa, Franco; University of Perugia, Department of Clinical and } \\
\text { Experimental Medicine } \\
\text { Bistoni, Giovanni; University of Perugia, Department of } \\
\text { Experimental Medicine and Biochemical Sciences } \\
\text { Casagrande, Andrea; University of Perugia, Department of } \\
\text { Experimental Medicine and Biochemical Sciences } \\
\text { Rodrigues, Fernando; University of Minho, School of Health } \\
\text { Sciences } \\
\text { Romani, Luigina; University of Perugia, Department of Experimental } \\
\text { Medicine and Biochemical Sciences } \\
\text { Carvalho, Agostinho; University of Perugia, Dep. of Experimental } \\
\text { Medicine and Biochemical Sciences }\end{array}$ \\
\hline \hline Keywords: & $\begin{array}{l}\text { Fungal disease, Genetic susceptibility, Pattern recognition } \\
\text { receptors, Inflammation }\end{array}$ \\
\hline \hline
\end{tabular}

\section{SCHOLARONE ${ }^{\text {M }}$ Manuscripts}




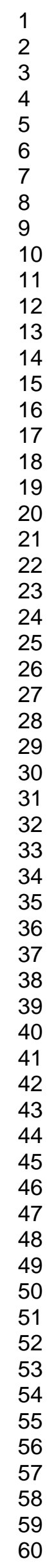
4 6 28 60 


\title{
Immunogenetic profiling to predict risk of invasive fungal diseases: where are we now?
}

\author{
Running head: Immunogenetics of invasive fungal diseases \\ Cristina Cunha ${ }^{1}$, Franco Aversa ${ }^{2}$, Giovanni Bistoni ${ }^{1}$, Andrea Casagrande ${ }^{1}$, Fernando \\ Rodrigues ${ }^{3}$, Luigina Romani ${ }^{1}$ and Agostinho Carvalho ${ }^{1,3}$
}

\author{
${ }^{1}$ Microbiology Section, Department of Experimental Medicine and Biochemical Sciences, \\ University of Perugia, Perugia, Italy \\ ${ }^{2}$ Division of Hematology and Clinical Immunology, Department of Clinical and Experimental \\ Medicine, University of Perugia, Perugia, Italy \\ ${ }^{3}$ Life and Health Sciences Research Institute (ICVS), School of Health Sciences, University of \\ Minho, Braga, Portugal
}

\begin{abstract}
Correspondence: Agostinho Carvalho, Microbiology Section, Department of Experimental Medicine and Biochemical Sciences, University of Perugia, Via del Giochetto, 06126 Perugia, Italy. Ph and Fax: +39075 5857498. E-mail: aacarvalho2008@gmail.com
\end{abstract}




\begin{abstract}
Invasive fungal diseases remain nowadays life-threatening conditions affecting multiple clinical settings. The onset of these diseases is dependent on numerous factors, of which the "immunocompromised" phenotype of the patients is the more often acknowledged. However, and despite comparable immune dysfunction, not all patients are ultimately susceptible to disease, suggesting that additional risk factors, likely of genetic nature, may also be important. In the last years, genetic variants in several immune-related genes have also been proposed as major determinants of the susceptibility pattern of high-risk patients to invasive fungal diseases. Altogether, these findings highlighted the crucial significance of the individual genetic make-up in defining susceptibility to infection, providing a compelling rationale for the introduction of the immunogenetic profile as a risk prediction measure that may ultimately help to guide clinicians in the use of prophylaxis and preemptive fungal therapy in high-risk patients.
\end{abstract}




\section{Introduction}

Fungal diseases are epidemiologically characteristic of high-risk groups. These include patients with hematological malignancies, prolonged and severe neutropenia, undergoing corticosteroid therapy or submitted to solid organ or stem cell transplantation, among others. However, besides the relative risk conferred by the "immunocompromised" phenotype as a result of the underlying condition or treatment scheme, certain individuals with specific, geneticallydetermined, immune defects are also more vulnerable to infection.

Over the last decades, considerable advances have been made in understanding the molecular bases determining disparate susceptibilities to infectious diseases in humans. Monogenetic defects underlying primary immunodeficiencies (PIDs) have been classically associated with predisposition to a restricted spectrum of fungal pathogens causing clinically defined manifestations. For example, the hyper-IgE syndrome (HIES) or the autoimmune polyendocrinopathy candidiasis ectodermal dystrophy (APECED) syndrome are usually correlated with susceptibility to superficial fungal infections, most remarkably chronic mucocutaneous candidiasis (CMC). On the other hand, chronic granulomatous disease (CGD), an inherited disorder of the phagocyte nicotinamide adenine dinucleotide phosphate (NADPH) oxidase complex that impairs the production of reactive oxygen species, predisposes to several recurrent life-threatening infections, of which invasive aspergillosis (IA) is the most distinctive fungal disease.

In addition to PIDs, other factors modifying risk of fungal disease are often genetic polymorphisms. These have a substantial allele prevalence in the general population but, under select contexts of immunocompromise typical of many clinical settings, may translate into a further severity of the immunological dysfunction, ultimately rendering these individuals more prone to disease. In this article, we review the contribution of genetic polymorphisms of the immune system to susceptibility to invasive fungal diseases and discuss how this knowledge may be used for the design of individually tailored approaches to be integrated in clinical practice. 


\section{Genetic defects of PRRs and susceptibility to invasive fungal diseases}

Invasive fungal diseases are usually devastating conditions associated with high mortality rates and that affect a broad range of patients with apparently disparate underlying risk factors (e.g. allogeneic stem cell transplant recipients). Given the need to predict risk for disease in these patients and design effective preventive strategies, a relatively large number of studies have investigated the association between genetic variants of pattern recognition receptors (PRRs) or inflammatory mediators and risk of invasive fungal diseases (Carvalho et al., 2010b) (Figure 1).

\section{Toll-like receptors (TLRs)}

TLRs participate in the recognition of microbial structures and in the initiation of inflammatory and antimicrobial host defenses. They are expressed in several cell types including, but not exclusively, monocytes, macrophages, dendritic cells and neutrophils, and can be predominantly expressed on the cell surface (TLR1, $-2,-4,-5$ and -6 ) or retained intracellularly in endosomes (TLR3, -7, -8 and -9). Recent evidence also attested a major contribution of TLRs present at epithelial surfaces to antimicrobial defense and immunosurveillance (Weindl et al., 2007; de Luca et al., 2010). Distinct TLR ligands are able to mediate disparate effector responses through the same receptor, a phenomenon in part explained by the selective usage of adapter molecules such as myeloid differentiation factor 88 (MyD88) and Toll/IL-1 receptor (TIR) domaincontaining adapter inducing interferon- $\beta$ (TRIF). Receptor engagement eventually culminates in the activation of transcription factors such as nuclear factor $\kappa \mathrm{B}(\mathrm{NF}-\mathrm{\kappa B})$ and members of the interferon regulatory factor (IRF) family, which successively induce gene expression and production of various cytokines, chemokines and molecules required for antigen presentation or costimulation.

The early finding that Toll-deficient Drosophila were unable to mount effective antifungal responses and were highly susceptible to infection by Aspergillus fumigatus highlighted a similar participation of mammalian TLRs in antifungal immunity. In fact, TLR2, -4 and -9 function has 
been categorically demonstrated to contribute to host responses against fungi both in mice and in humans (Cunha et al., 2010c). Given its crucial role in the immune response to fungi, TLR4 has been regarded as one major potential repository of genetic variability contributing to susceptibility to fungal diseases. For this reason, most studies performed to date have focused on the highly polymorphic TLR4 gene, in which two nonsynonymous polymorphisms - D299G and T399I - have been linked with blunted responses to inhaled lipopolysaccharide (Arbour et al., 2000).

A donor haplotype in TLR4 consisting of the above-mentioned polymorphisms was disclosed as an independent predictive factor for IA among unrelated hematopoietic stem cell transplant (HSCT) recipients (Bochud et al., 2008). Although alternative explanations for this association have been proposed, namely the possible interaction of TLR4 with cytomegalovirus (CMV) (Cervera et al., 2009) or antifungal drugs (Levitz et al., 2009), the D299G and T399I polymorphisms have been linked with susceptibility to pulmonary aspergillosis in nontransplanted patients, who are not susceptible to CMV disease and usually do not receive antifungal prophylaxis (Carvalho et al., 2008). In addition, we have reported an association of the TLR4 haplotype with fungal colonization following T-cell-depleted transplantation, although without increased risk for invasive disease (Carvalho et al., 2009). A previous study had also failed to associate TLR4 polymorphisms with IA in HSCT recipients, despite evidence pointing to a role of genetic variants in TLR1 and TLR6 (Kesh et al., 2005). These discrepancies between studies further stress that the contribution of genetic variants to IA may depend on several factors, such as the type of transplant and associated demographic and clinical co-variables. Uncovering the biological implications of TLR4 polymorphisms in the immune response to Aspergillus would ultimately strengthen the clinical repercussions of these findings. It is worth mentioning that polymorphisms in TLR2 and TLR9 were not associated with IA (Bochud et al., 2008; Carvalho et al., 2009), although a common promoter polymorphism in TLR9 (-1237T >C) was shown to predispose to allergic bronchopulmonary aspergillosis (Carvalho et al., 2008). 


\section{1}

However, it also holds true that the absence of association should always be interpreted in the scope of the limited power of the existing studies.

The TLR4 haplotype had also been suggested to contribute to a higher risk of Candida bloodstream infection (Van der Graaf et al., 2006). However, this underpowered report has been recently challenged by a study from the same group in a large cohort of patients with invasive candidiasis (IC), which excluded any role of these genetic variants in susceptibility to this disease (Plantinga et al., 2009a). Instead, polymorphisms in TLR1 were shown to be strong predictive markers for IC and functional assays demonstrated that the increased risk was associated with impaired production of cytokines such as IL-1 $\beta$, IL-6 and IL-8. Although this provides proof of concept that TLR1 plays a major role in the pathogenesis of IC, it is of note that this study dealt only with nonsynonymous polymorphisms and thus, does not exclude additional genetic variability potentially impacting susceptibility to this disease.

In addition, and despite no studies have revealed an association between genetic variants in TLR2 and candidiasis, the nonsynonymous polymorphism R753Q was shown to modulate cytokine release during Candida sepsis in intensive care unit patients (Woehrle et al., 2008). The extent to which the deregulated cytokine production contributes to susceptibility to candidiasis is however still not clear.

\section{C-type lectin receptors (CLRs)}

Even though the signaling pathways elicited by TLRs are crucial for the control of fungal infection (Bellocchio et al., 2004), a pivotal role for dectin-1 as the prototype of innate non-TLR signaling pathway for antifungal sensing has been highlighted (Brown, 2006). Dectin-1 is a CLR that specifically recognizes the cell wall carbohydrate $\beta-(1,3)$-glucan of many fungi and mediates cell activation, cytokine production and a variety of antifungal responses either through the spleen tyrosine kinase Syk/cytoplasmic caspase recruiting domain 9 (CARD9) (LeibundGutLandmann et al., 2007) or Raf-1 (Gringhuis et al., 2009) pathways. 
Polymorphisms in the gene encoding for dectin- 1 have also been recently addressed as potential predictive factors for the incidence of fungal diseases. In particular, the early stop codon polymorphism Y238X has been found to associate with recurrent mucocutaneous fungal infections (Ferwerda et al., 2009) and to contribute to Candida colonization after HSCT (Plantinga et al., 2009b). This susceptibility phenotype was correlated with the generation of a truncated dectin-1 protein unable to target the membrane, thereby restraining $\beta$-glucan binding by monocytes and resulting in defective cytokine production upon receptor engagement, in particular IL-17 (Ferwerda et al., 2009; Plantinga et al., 2009b). Interestingly, a similar susceptibility pattern to mucocutaneous infections related to a deficit in IL-17 production was also found in a family carrying loss-of-function mutations in CARD9 (Glocker et al., 2009), suggesting that disruption of dectin- 1 signaling and concomitant failure to produce IL-17 in response to Candida critically impairs mucosal antifungal defense. Accordingly, the clinical manifestation of CMC was also recently found to rely on genetic defects in IL17F and IL17RA (Puel et al., 2011).

Work from our group has also demonstrated that dectin-1 deficiency contributed as well to an increased susceptibility to IA following HSCT, an association which relied on either recipient or donor genetic make-ups and to be synergistically increased in polymorphic recipient/donor pairs (Cunha et al., 2010a). Another study has instead proposed a limited influence of the Y238X polymorphism on susceptibility to IA, in particular in non-HSCT patients (Chai et al., 2011). This study however failed to address the likely confounding effects of population stratification on their conclusions given the enrollment of admixed heterogeneous patient populations. Larger, well-designed studies, preferably performed on consecutive patients, are ultimately required to clarify the role of the Y238X polymorphism in both HSCT and non-HSCT patients at risk of IA.

Although dectin-1 has been regarded as one major innate receptor leading to T helper 17 (Th17) activation in response to Aspergillus (Werner et al., 2009), production of IFN- $\gamma$ and IL-10 by dectin-1-deficient peripheral blood mononuclear cells, more than IL-17, was found to be 


\section{Other PRRs}

The collectin subfamily of lectins includes members such as mannose-binding lectin (MBL), pentraxin 3 (PTX3) and the lung surfactant proteins (SPs). Collectins are able to bind to fungi and activate the complement system leading to their opsonization or direct killing. Among this class of PRRs, MBL is the most extensively dissected member from a genetic point of view. A combination of structural and promoter polymorphisms is known to exist in the $M B L 2$ gene and each may define the levels of functional protein (Garred, 2008). For this reason, since it was first reported, MBL deficiency has been consistently associated with increased susceptibility to infections, particularly when adaptive immunity is impaired. Accordingly, reduced levels of MBL have been recently correlated with the incidence of acute IA in non-HSCT immunocompromised patients, despite no causal nature was attributed to MBL polymorphisms (Lambourne et al., 2009). Nevertheless, donor $M B L 2^{\text {low }}$ genotypes (O/O or LXA/O) have been identified as important predictive factors of increased incidence of invasive fungal diseases after HSCT (Granell et al., 2006). Similarly, the nonsynonymous polymorphism D105G in recipient MBLassociated serine protease 2 gene (MASP2), known to hinder MBL function, was also linked with invasive fungal disease after HSCT (Granell et al., 2006). However, the later finding deserves additional validation owing to the low number of recipients with the MASP2 variant. 
In addition to MBL, genetic mapping analysis of the survival data of an immunocompromised mice model has also allowed the identification of plasminogen, a regulatory molecule that binds to Aspergillus, as a suitable candidate gene for aspergillosis susceptibility (Zaas et al., 2008). The clinical translation of these findings acknowledged the nonsynonymous polymorphism $\mathrm{D} 472 \mathrm{~N}$ in the human gene encoding for plasminogen to influence the risk of developing IA in HSCT recipients, particularly late after transplantation. Besides shedding light into the role of the fibrinolytic system in the pathogenesis of IA, this computational approach identified a novel and biologically plausible candidate gene for susceptibility to IA, therefore validating its future use in the identification of less obvious fungal disease-related genes.

\section{Cytokines/chemokines}

Cytokines mediate the inflammatory and adaptive immune responses to pathogens. Whereas inflammation may serve to limit infection, when heightened, it may significantly contribute to pathogenicity, as documented by the elevated incidence of severe fungal infections in patients with immune reconstitution syndrome (Singh and Perfect, 2007). It is not surprising therefore that patients with inborn errors in the IL-12/IFN- $\gamma$ axis, unable to mount proper inflammatory responses, are highly susceptible to disseminated fungal diseases such as paracoccidioidomycosis (PCM) (Moraes-Vasconcelos et al., 2005) and histoplasmosis (Zerbe and Holland, 2005).

Genetic variants in cytokine genes have been considered crucial factors determining vulnerability to fungal infections, particularly aspergillosis. In this regard, IL-10 has been considered one major candidate for genetic studies as its production has been suggested to be largely genetically-determined, in part due to the promoter polymorphism $-1082 \mathrm{G}>\mathrm{A}$. Indeed, patient IL10 low genotypes were shown to confer protection from IA in both HSCT (Seo et al., 2005) and non-HSCT (Sainz et al., 2007a) patients. Despite the fact that no actual correlation with serum levels was established in these studies, the validity of these associations is fairly 
reinforced by the finding that $I L 10^{\text {high }}$ genotypes were instead linked with increased colonization with Aspergillus and allergic disease in patients with cystic fibrosis (Brouard et al., 2005). Similarly, increased production of IL-10 resulting from IL10 high genotypes has also been shown to contribute to the development of chronic fungal infections such as PCM (Bozzi et al., 2006). Hence, and regardless of the lack of functional data definitely correlating IL10 polymorphisms with impaired immune responses to Aspergillus, the consistency of the associations based on genotype-defined IL-10 levels reflects the likely role of these polymorphisms in determining resistance versus susceptibility to aspergillosis.

A small number of other studies have addressed the role of polymorphisms in additional cytokines and/or their receptors as predisposing factors to IA. For example, and despite analysis of individual locus failed to associate variants in the genes encoding for IL- $1 \alpha$, IL-1 $\beta$ and IL-1R antagonist (IL-1Ra) with IA, a polymorphism haplotype in this gene cluster (VNTR2/-889C/511T) was nevertheless strongly associated with susceptibility to this disease in hematological patients (Sainz et al., 2008). Work from the same group has also demonstrated a crucial contribution of polymorphisms in the TNF receptor 1 (TNFR1) and 2 (TNFR2) to an increased susceptibility to IA in non-HSCT patients (Sainz et al., 2007b; Sainz et al., 2010). In this case, and particularly regarding TNFR1, the observed susceptibility to IA was correlated with defective receptor expression, suggesting a crucial contribution of TNF- $\alpha$ signaling in the immune response to Aspergillus, at least in this particular setting of patients.

In addition, we have found that the functional polymorphism R381Q affecting the receptor for IL-23 (IL-23R) instead conferred a protective effect regarding IA and correlated with improved survival of HSCT recipients (Carvalho et al., 2010a). Functionally, this specific polymorphism has been demonstrated to promote a deficient activation of IL-23-driven Th17 responses (Cunha et al., 2010b). Interestingly, whereas committed effector Th17 cells derived from subjects harboring R381Q stimulated with IL-23 had an impaired production of IL-17, highly purified naïve T-cells did not, suggesting that the consequences of the polymorphism may be exclusively reflected in the function of differentiated Th17 cells. 
Recently, data has also pointed to the relevance of genetic variants in chemokine genes in host susceptibility to fungal diseases. A large-scale screening of polymorphisms led to the finding of a haplotype in CXC chemokine ligand 10 (CXCL10) resulting in increased susceptibility to IA in HSCT recipients (Mezger et al., 2008). Mechanistically, immature wild-type dendritic cells exposed to A. fumigatus showed a markedly increase in CXCL10 expression, in contrast to those harboring the risk haplotype. In this regard, it is also interesting to note that patients who survived IA had significantly higher CXCL10 levels in comparison to healthy controls.

Altogether, and despite the need for replication studies in independent cohorts of patients, these findings point to the importance of maintaining a finely orchestrated balance between pro- and anti-inflammatory signals, fundamental for the immune system to effectively attack and eliminate pathogenic fungi, suggesting that the disruption of this equilibrium may ultimately underlie an increased predisposition to IA.

\section{Immunogenetics of invasive fungal diseases: what does the future hold?}

The dissection of the genetic bases underlying susceptibility to infectious diseases inspires a very active, yet complex, field of research. As the awareness of the individual genetic make-up may hold the key to expose unsuspected risk factors for these diseases, the current understanding of the immunological network involved in the immune response to pathogens needs to be addressed also from a genetic point of view. Given that the modulation of host immune responses has been regarded as a potential therapeutic target for the eradication of fungal diseases, knowing each individual's immunogenetic profile, together with the application of promising therapeutic strategies such as siRNA delivery (Bonifazi et al., 2010), could prove critical for the design of novel, effective fungal vaccines capable of targeting and exerting control over the outcome of specific signalling pathways.

Although many of the studies published so far still lack replication, a step forward in this field would be provided by large-scale translational and clinical studies validating the data obtained from the genetic analyses. This would support the use of genetic screening of at-risk 
patients and would ultimately allow the individualization of prophylaxis and treatments by means of targeted and patient-tailored approaches likely improving the management and outcome of these severe, often fatal diseases.

\section{Acknowledgements}

This work was supported by the Specific Targeted Research Projects "ALLFUN" (FP7-HEALTH2010-single-stage, contract number 260338) and "SYBARIS" (FP7-HEALTH-2009-single-stage contract number 037899) (FP7), and by the Fondazione per la Ricerca sulla Fibrosi Cistica (Project number FFC\#21/2010). Cristina Cunha and Agostinho Carvalho were financially supported by fellowships from Fundação para a Ciência e Tecnologia, Portugal (contracts SFRH/BD/65962/2009 and SFRH/BPD/46292/2008, respectively).

\section{Declaration of interest}

The authors report no conflicts of interest. The authors alone are responsible for the content and writing of the paper.

\section{Figure legends}

Figure 1. Genetic polymorphisms of pattern recognition receptors (PRRs) and inflammatory mediators associated with susceptibility to invasive fungal diseases. 


\section{References}

Arbour, N.C., Lorenz, E., Schutte, B.C., Zabner, J., Kline, J.N., Jones, M., Frees, K., Watt, J.L., and Schwartz, D.A. (2000). TLR4 mutations are associated with endotoxin hyporesponsiveness in humans. Nat Genet 25, 187-191.

Bellocchio, S., Montagnoli, C., Bozza, S., Gaziano, R., Rossi, G., Mambula, S.S., Vecchi, A., Mantovani, A., Levitz, S.M., and Romani, L. (2004). The contribution of the Toll-like/IL-1 receptor superfamily to innate and adaptive immunity to fungal pathogens in vivo. J Immunol 172, 30593069.

Bochud, P.Y., Chien, J.W., Marr, K.A., Leisenring, W.M., Upton, A., Janer, M., Rodrigues, S.D., Li, S., Hansen, J.A., Zhao, L.P., Aderem, A., and Boeckh, M. (2008). Toll-like receptor 4 polymorphisms and aspergillosis in stem-cell transplantation. N Engl J Med 359, 1766-1777.

Bonifazi, P., D'Angelo, C., Zagarella, S., Zelante, T., Bozza, S., De Luca, A., Giovannini, G., Moretti, S., Iannitti, R.G., Fallarino, F., Carvalho, A., Cunha, C., Bistoni, F., and Romani, L. (2010). Intranasally delivered siRNA targeting PI3K/Akt/mTOR inflammatory pathways protects from aspergillosis. Mucosal Immunol 3, 193-205.

Bozzi, A., Pereira, P.P., Reis, B.S., Goulart, M.I., Pereira, M.C., Pedroso, E.P., Leite, M.F., and Goes, A.M. (2006). Interleukin-10 and tumor necrosis factor-alpha single nucleotide gene polymorphism frequency in paracoccidioidomycosis. Hum Immunol 67, 931-939.

Brouard, J., Knauer, N., Boelle, P.Y., Corvol, H., Henrion-Caude, A., Flamant, C., Bremont, F., Delaisi, B., Duhamel, J.F., Marguet, C., Roussey, M., Miesch, M.C., Chadelat, K., Boule, M., Fauroux, B., Ratjen, F., Grasemann, H., and Clement, A. (2005). Influence of interleukin-10 on Aspergillus fumigatus infection in patients with cystic fibrosis. J Infect Dis 191, 1988-1991.

Brown, G.D. (2006). Dectin-1: a signalling non-TLR pattern-recognition receptor. Nat Rev Immunol 6, 33-43.

Carvalho, A., Cunha, C., Carotti, A., Aloisi, T., Guarrera, O., Di Ianni, M., Falzetti, F., Bistoni, F., Aversa, F., Pitzurra, L., Rodrigues, F., and Romani, L. (2009). Polymorphisms in Toll-like receptor 
genes and susceptibility to infections in allogeneic stem cell transplantation. Exp Hematol 37, 1022-1029.

Carvalho, A., Cunha, C., Di Ianni, M., Pitzurra, L., Aloisi, T., Falzetti, F., Carotti, A., Bistoni, F., Aversa, F., and Romani, L. (2010a). Prognostic significance of genetic variants in the IL-23/Th17 pathway for the outcome of $\mathrm{T}$ cell-depleted allogeneic stem cell transplantation. Bone Marrow Transplant 45, 1645-1652.

Carvalho, A., Cunha, C., Pasqualotto, A.C., Pitzurra, L., Denning, D.W., and Romani, L. (2010b). Genetic variability of innate immunity impacts human susceptibility to fungal diseases. Int J Infect Dis 14, e460-468.

Carvalho, A., Pasqualotto, A.C., Pitzurra, L., Romani, L., Denning, D.W., and Rodrigues, F. (2008). Polymorphisms in toll-like receptor genes and susceptibility to pulmonary aspergillosis. J Infect Dis 197, 618-621.

Cervera, C., Moreno, A., and Lozano, F. (2009). Toll-like receptor 4 polymorphisms and aspergillosis. N Engl J Med 360, 634-635; author reply 635-636.

Chai, L.Y., de Boer, M.G., van der Velden, W.J., Plantinga, T.S., van Spriel, A.B., Jacobs, C., Halkes, C.J., Vonk, A.G., Blijlevens, N.M., van Dissel, J.T., Donnelly, P.J., Kullberg, B.J., Maertens, J., and Netea, M.G. (2011). The Y238X Stop Codon Polymorphism in the Human \{beta\}-Glucan Receptor Dectin-1 and Susceptibility to Invasive Aspergillosis. J Infect Dis 203, 736-743.

Cunha, C., Di Ianni, M., Bozza, S., Giovannini, G., Zagarella, S., Zelante, T., D'Angelo, C., Pierini, A., Pitzurra, L., Falzetti, F., Carotti, A., Perruccio, K., Latge, J.P., Rodrigues, F., Velardi, A., Aversa, F., Romani, L., and Carvalho, A. (2010a). Dectin-1 Y238X polymorphism associates with susceptibility to invasive aspergillosis in hematopoietic transplantation through impairment of both recipient- and donor-dependent mechanisms of antifungal immunity. Blood 116, 53945402.

Cunha, C., Rodrigues, F., Zelante, T., Aversa, F., Romani, L., and Carvalho, A. (2010b). Genetic susceptibility to aspergillosis in allogeneic stem-cell transplantation. Med Mycol. 
Cunha, C., Romani, L., and Carvalho, A. (2010c). Cracking the Toll-like receptor code in fungal infections. Expert Rev Anti Infect Ther 8, 1121-1137.

de Luca, A., Bozza, S., Zelante, T., Zagarella, S., D'Angelo, C., Perruccio, K., Vacca, C., Carvalho, A., Cunha, C., Aversa, F., and Romani, L. (2010). Non-hematopoietic cells contribute to protective tolerance to Aspergillus fumigatus via a TRIF pathway converging on IDO. Cell Mol Immunol 7, 459-470.

Ferwerda, B., Ferwerda, G., Plantinga, T.S., Willment, J.A., van Spriel, A.B., Venselaar, H., Elbers, C.C., Johnson, M.D., Cambi, A., Huysamen, C., Jacobs, L., Jansen, T., Verheijen, K., Masthoff, L., Morre, S.A., Vriend, G., Williams, D.L., Perfect, J.R., Joosten, L.A., Wijmenga, C., van der Meer, J.W., Adema, G.J., Kullberg, B.J., Brown, G.D., and Netea, M.G. (2009). Human dectin-1 deficiency and mucocutaneous fungal infections. N Engl J Med 361, 1760-1767.

Garred, P. (2008). Mannose-binding lectin genetics: from A to Z. Biochem Soc Trans 36, 14611466.

Glocker, E.O., Hennigs, A., Nabavi, M., Schaffer, A.A., Woellner, C., Salzer, U., Pfeifer, D., Veelken, H., Warnatz, K., Tahami, F., Jamal, S., Manguiat, A., Rezaei, N., Amirzargar, A.A., Plebani, A., Hannesschlager, N., Gross, O., Ruland, J., and Grimbacher, B. (2009). A homozygous CARD9 mutation in a family with susceptibility to fungal infections. N Engl J Med 361, 1727-1735.

Granell, M., Urbano-Ispizua, A., Suarez, B., Rovira, M., Fernandez-Aviles, F., Martinez, C., Ortega, M., Uriburu, C., Gaya, A., Roncero, J.M., Navarro, A., Carreras, E., Mensa, J., Vives, J., Rozman, C., Montserrat, E., and Lozano, F. (2006). Mannan-binding lectin pathway deficiencies and invasive fungal infections following allogeneic stem cell transplantation. Exp Hematol 34, 1435-1441.

Gringhuis, S.I., den Dunnen, J., Litjens, M., van der Vlist, M., Wevers, B., Bruijns, S.C., and Geijtenbeek, T.B. (2009). Dectin-1 directs $\mathrm{T}$ helper cell differentiation by controlling noncanonical NF-kappaB activation through Raf-1 and Syk. Nat Immunol 10, 203-213.

Kesh, S., Mensah, N.Y., Peterlongo, P., Jaffe, D., Hsu, K., M, V.D.B., O'Reilly, R., Pamer, E., Satagopan, J., and Papanicolaou, G.A. (2005). TLR1 and TLR6 polymorphisms are associated with 
susceptibility to invasive aspergillosis after allogeneic stem cell transplantation. Ann N Y Acad Sci 1062, 95-103.

Lambourne, J., Agranoff, D., Herbrecht, R., Troke, P.F., Buchbinder, A., Willis, F., Letscher-Bru, V., Agrawal, S., Doffman, S., Johnson, E., White, P.L., Barnes, R.A., Griffin, G., Lindsay, J.A., and Harrison, T.S. (2009). Association of mannose-binding lectin deficiency with acute invasive aspergillosis in immunocompromised patients. Clin Infect Dis 49, 1486-1491.

LeibundGut-Landmann, S., Gross, O., Robinson, M.J., Osorio, F., Slack, E.C., Tsoni, S.V., Schweighoffer, E., Tybulewicz, V., Brown, G.D., Ruland, J., and Reis e Sousa, C. (2007). Syk- and CARD9-dependent coupling of innate immunity to the induction of $\mathrm{T}$ helper cells that produce interleukin 17. Nat Immunol 8, 630-638.

Levitz, S.M., Shoham, S., and Cleary, J.D. (2009). Toll-like receptor 4 polymorphisms and aspergillosis. N Engl J Med 360, 634; author reply 635-636.

Mezger, M., Steffens, M., Beyer, M., Manger, C., Eberle, J., Toliat, M.R., Wienker, T.F., Ljungman, P., Hebart, H., Dornbusch, H.J., Einsele, H., and Loeffler, J. (2008). Polymorphisms in the chemokine (C-X-C motif) ligand 10 are associated with invasive aspergillosis after allogeneic stem-cell transplantation and influence CXCL10 expression in monocyte-derived dendritic cells. Blood $111,534-536$.

Moraes-Vasconcelos, D., Grumach, A.S., Yamaguti, A., Andrade, M.E., Fieschi, C., de Beaucoudrey, L., Casanova, J.L., and Duarte, A.J. (2005). Paracoccidioides brasiliensis disseminated disease in a patient with inherited deficiency in the beta1 subunit of the interleukin (IL)-12/IL-23 receptor. Clin Infect Dis 41, e31-37.

Plantinga, T.S., Johnsson, M., Scott, B., van de Vosse, E., Velez, D., van der Meer, J.W.M., van Dissel, J., Perfect, J., Kullberg, B.J., and Netea, M.G. (2009a). Toll like receptor 1 polymorphisms and susceptibility to invasive candidiasis. Sepsis 13 (Suppl 4), P28.

Plantinga, T.S., van der Velden, W.J., Ferwerda, B., van Spriel, A.B., Adema, G., Feuth, T., Donnelly, J.P., Brown, G.D., Kullberg, B.J., Blijlevens, N.M., and Netea, M.G. (2009b). Early stop 
polymorphism in human DECTIN-1 is associated with increased candida colonization in hematopoietic stem cell transplant recipients. Clin Infect Dis 49, 724-732.

Puel, A., Cypowyj, S., Bustamante, J., Wright, J.F., Liu, L., Lim, H.K., Migaud, M., Israel, L., Chrabieh, M., Audry, M., Gumbleton, M., Toulon, A., Bodemer, C., El-Baghdadi, J., Whitters, M., Paradis, T., Brooks, J., Collins, M., Wolfman, N.M., Al-Muhsen, S., Galicchio, M., Abel, L., Picard, C., and Casanova, J.L. (2011). Chronic Mucocutaneous Candidiasis in Humans with Inborn Errors of Interleukin-17 Immunity. Science.

Sainz, J., Hassan, L., Perez, E., Romero, A., Moratalla, A., Lopez-Fernandez, E., Oyonarte, S., and Jurado, M. (2007a). Interleukin-10 promoter polymorphism as risk factor to develop invasive pulmonary aspergillosis. Immunol Lett 109, 76-82.

Sainz, J., Perez, E., Gomez-Lopera, S., and Jurado, M. (2008). IL1 gene cluster polymorphisms and its haplotypes may predict the risk to develop invasive pulmonary aspergillosis and modulate Creactive protein level. J Clin Immunol 28, 473-485.

Sainz, J., Perez, E., Hassan, L., Moratalla, A., Romero, A., Collado, M.D., and Jurado, M. (2007b). Variable number of tandem repeats of TNF receptor type 2 promoter as genetic biomarker of susceptibility to develop invasive pulmonary aspergillosis. Hum Immunol 68, 41-50.

Sainz, J., Salas-Alvarado, I., Lopez-Fernandez, E., Olmedo, C., Comino, A., Garcia, F., Blanco, A., Gomez-Lopera, S., Oyonarte, S., Bueno, P., and Jurado, M. (2010). TNFR1 mRNA expression level and TNFR1 gene polymorphisms are predictive markers for susceptibility to develop invasive pulmonary aspergillosis. Int J Immunopathol Pharmacol 23, 423-436.

Seo, K.W., Kim, D.H., Sohn, S.K., Lee, N.Y., Chang, H.H., Kim, S.W., Jeon, S.B., Baek, J.H., Kim, J.G., Suh, J.S., and Lee, K.B. (2005). Protective role of interleukin-10 promoter gene polymorphism in the pathogenesis of invasive pulmonary aspergillosis after allogeneic stem cell transplantation. Bone Marrow Transplant 36, 1089-1095.

Singh, N., and Perfect, J.R. (2007). Immune reconstitution syndrome associated with opportunistic mycoses. Lancet Infect Dis 7, 395-401. 
Van der Graaf, C.A., Netea, M.G., Morre, S.A., Den Heijer, M., Verweij, P.E., Van der Meer, J.W., and Kullberg, B.J. (2006). Toll-like receptor 4 Asp299Gly/Thr399Ile polymorphisms are a risk factor for Candida bloodstream infection. Eur Cytokine Netw 17, 29-34.

Weindl, G., Naglik, J.R., Kaesler, S., Biedermann, T., Hube, B., Korting, H.C., and Schaller, M. (2007). Human epithelial cells establish direct antifungal defense through TLR4-mediated signaling. J Clin Invest 117, 3664-3672.

Werner, J.L., Metz, A.E., Horn, D., Schoeb, T.R., Hewitt, M.M., Schwiebert, L.M., Faro-Trindade, I., Brown, G.D., and Steele, C. (2009). Requisite role for the dectin-1 beta-glucan receptor in pulmonary defense against Aspergillus fumigatus. J Immunol 182, 4938-4946.

Woehrle, T., Du, W., Goetz, A., Hsu, H.Y., Joos, T.O., Weiss, M., Bauer, U., Brueckner, U.B., and Marion Schneider, E. (2008). Pathogen specific cytokine release reveals an effect of TLR2 Arg753Gln during Candida sepsis in humans. Cytokine 41, 322-329.

Zaas, A.K., Liao, G., Chien, J.W., Weinberg, C., Shore, D., Giles, S.S., Marr, K.A., Usuka, J., Burch, L.H., Perera, L., Perfect, J.R., Peltz, G., and Schwartz, D.A. (2008). Plasminogen alleles influence susceptibility to invasive aspergillosis. PLoS Genet 4, e1000101.

Zerbe, C.S., and Holland, S.M. (2005). Disseminated histoplasmosis in persons with interferongamma receptor 1 deficiency. Clin Infect Dis 41, e38-41. 
Figure 1. Genetic polymorphisms of pattern recognition receptors (PRRs) and inflammatory mediators associated with susceptibility to invasive fungal diseases. $243 \times 114 \mathrm{~mm}(300 \times 300$ DPI) 